\title{
Night of the Animals A Christmas Eve Reading/Liturgy
}

(for 8 voices and congregation)

\author{
Paulette Callen \\ New York, New York
}
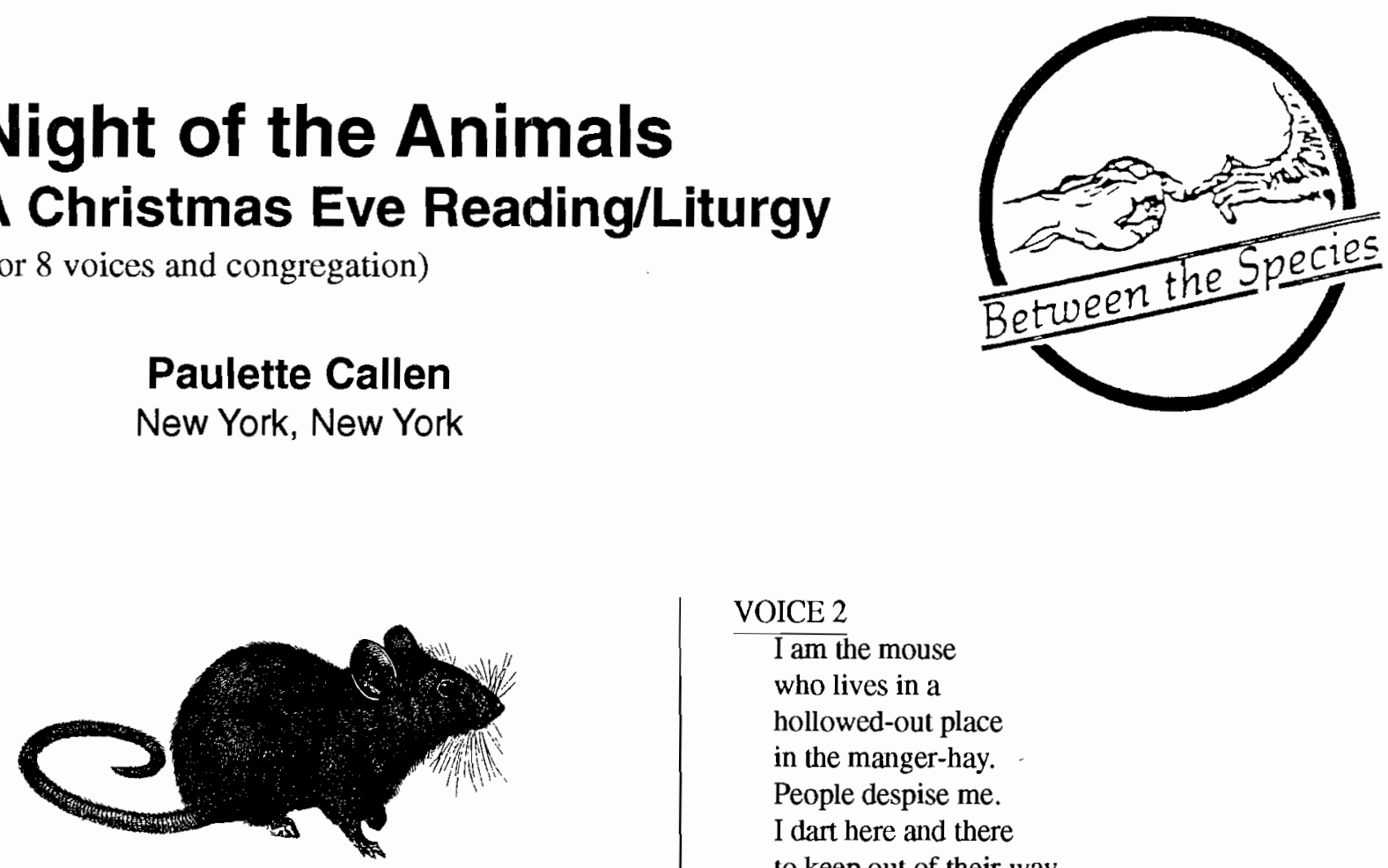

\section{VOICE 1}

I am the black snake

coiled under the straw

in the corner of the stable.

I stay well hidden

for people despise me.

I don't have a pretty face.

I am afraid of the man

who is with the woman.

(She is tired

having had a long journey-

this the donkey tells me.)

Now, the man comes close

and drops his bundles in this corner.

I have no chance to slip away!

He sees me here

coiled in this corner.

I wait in fear for him

to strike me with his staff.

I have no chance to slip away.

But--he smiles and says,

"I see. This is your space, Friend.

I'll put my bundles over there."

VOICE 2

I am the mouse

who lives in a

hollowed-out place

in the manger-hay.

People despise me.

I dart here and there

to keep out of their way.

I keep well hidden and quiet

so I will not frighten the woman.

She has come a long way

(so the donkey tells me).

But the man reaches deep

in the manger and picks up the hay

for the donkey. I barely escape

and fall back down.

I am afraid

for they know now I am here.

But-the woman says,

"Careful, Joseph.

Don't hurt that mouse."

\section{VOICE 3}

I am the gray spider

who sees from my silver web

high in the corner of the stable

a man and a woman come to rest

after a long, long journey

(the donkey tells me this).

I keep well back in the shadows

for I don't have a pretty face.

But now! I step out

upon my quivering web

to see what the wonder is

for I hear the heavens singing

and the oceans, too, from far away, 
and there, below me,

a small one opens His eyes.

He looks straight up at me.

I think-He smiles at me.

\section{VOICE 4}

I am the brown bat

that hangs from the rafters

of the stable. I sleep

in the shadows and fly in the night.

For people despise me.

I don't have a pretty face.

I come home to the solitude and safety

of my rafters--but I see them

in the stable - a man,

a woman, a babe, and a donkey.

I flutter in the doorway.

I don't know what to do.

I can't stay out here

for the day will come,

and if I stay out here

people will kill me with stones,

and I cannot go in

for I am afraid.

The woman looks up at me

fluttering in the doorway.

She says, "Come in, Little One.

This is your home. We are only visitors and will not disturb you too much."

\section{VOICES 1, 2, 3, 4 IN UNISON}

We raise our heads

and creep out of the shadows,

for we hear the heavens ringing

and the oceans, too, from far away,

and we know.

And we gather at the feet

of the woman and the babe.

They do not drive us away even though we are despised.

The woman says, "Joseph, look.

They've come to see.

Aren't they lovely?"

VOICE 1

Me! The snake.

\section{VOICE 4}

Me! The bat.

\section{VOICE 3}

Me! The spider

\section{VOICE 2}

Me! The mouse.

\section{ALL VOICES 1-4 IN UNISON}

Lovely!!

We gather to see the Babe, the Creator's Appointed One.

\section{VOICE 5}

The animals know when the storm will break

\section{VOICE 6}

The animals know when the earth will quake

\section{VOICE 7}

And the animals knew that He was coming, the Creator's Appointed One.

\section{VOICE 5}

They didn't need the angels to tell them, they knew.

\section{ALL VOICES 5, 6, 7}

Because animals know such things.

LEADER: The camels needed no rein to tell them where to go.

RESPONSE: (congregation) The Wise Men were not so wise. They needed the star.

LEADER: The goats needed no gathering, the sheep no herding. They were ready to come down from the hills.

RESPONSE: They would have come down from the hills with or without the shepherds.

LEADER: And what of those who were not in Bethlehem?

RESPONSE: Of course, they knew when the Babe was born, the Creator's Appointed One.

LEADER: When the Babe was born, the Creator's Appointed One

RESPONSE: the whales began to sing.

LEADER: From waters warm to waters cold

RESPONSE: the oceans rang with song beneath the crystal sky. 
LEADER: When the babe was born, the Creator's Appointed One,

RESPONSE: the cats began to purr. A rumble spread across the earth.

LEADER: Little cats in barns and window sills, jungle cats, tree cats, mountain cats purred-

RESPONSE: purred until the earth vibrated with joy.

LEADER: The wolves threw back their heads and raised voices to the sky.

RESPONSE:Some howled under a rising moon,

LEADER: Some into the sun, some to the star itself. They sang for joy,

RESPONSE: for the birth of the Babe, the Creator's Appointed One.

LEADER: Butterflies in many colors took flight

RESPONSE: and made fluttering rainbows across the skies.

LEADER: The frogs drummed in the ponds;

RESPONSE: the crickets clicked from tall grasses,

LEADER: birds filled the treetops with sweet music,

RESPONSE: when the Babe was born, the Creator's Appointed One.

\section{ALL VOICES IN UNISON}

The valleys, the mountains, the woods, the grasslands, the seas, and the skies rang out, for the animals knew of the birth of the Babe, the Creator's Appointed One.

LEADER: Horses neighed and stamped in pride that one of their own cousins had carried the Babe.

RESPONSE: and would carry Him again, as a man.

ALL: The animals knew.

LEADER: The gorillas poised silently

RESPONSE: under the green canopy of their mountain home,

LEADER: for they knew and were quiet, with only the beating of their great, gentle hearts to resonate joy

RESPONSE: at the birth of the Babe, the Creator's Appointed One.
ALL VOICES:

The animals knew.

\section{VOICE 8}

And they knew why He came as a human and not as one of them; for humans are a needy bunch and what they need most is teaching.

\section{VOICE 7}

Humans need to be taught love

RESPONSE: For it does not come naturally to them as to the wolf,

VOICE 6

Humans need to be taught justice

RESPONSE: for it does not come naturally to them as to the elephant.

\section{VOICE 5}

Humans need to be taught wisdom

RESPONSE: for it does not come naturally to them as to the bear.

VOICE 4

Humans need to be taught forgiveness

RESPONSE: for it does not come naturally to them as to the cow.

VOICE 3

Humans need to be taught a way to find our own peace RESPONSE: for it does not come naturally to us as to the other animals.

VOICE 2

And so was born the Chosen One,

VOICE 1

the Anointed One,

\section{AIL VOICES 1-7}

The Son,

\section{VOICE 8}

to teach us all the things the animals know but humans have forgotten.

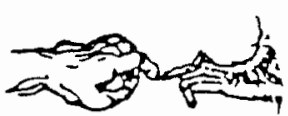

